\title{
Reversible inhibition of mitochondrial complex IV activity in PBMC following acute smoking
}

\author{
J-R. Alonso, F. Cardellach, J. Casademont, Ò. Miró
}

Reversible inhibition of mitochondrial complex IV activity in PBMC following acute smoking. J-R. Alonso, F. Cardellach, J. Casademont, Ò. Miró. (C)ERS Journals Ltd 2004.

ABSTRACT: Smoking causes a decrease of mitochondrial complex IV activity in chronic smokers. However, it is not known if this toxic effect is due to the acute effect of cigarette smoke itself or is a secondary phenomenon related to other smoking factors.

The study assessed mitochondrial respiratory chain function in peripheral blood mononuclear cells of 15 healthy nonsmoker individuals before smoking (to), immediately after smoking five cigarettes in $45 \mathrm{~min}$ (t1) and $24 \mathrm{~h}$ later (t2). Blood carboxyhaemoglobin $(\mathrm{COHb})$ and carbon monoxide concentrations in exhaled air (COEA) were determined to ascertain smoke inhalation status.

After acute smoking, COHb increased from $0.5 \pm 0.3 \%$ to $3.3 \pm 1.5 \%$, and COEA from 2.9 \pm 2.5 to $26.1 \pm 9.9 \mathrm{ppm}$. Complex II and III enzyme activities did not change along the study. Complex IV activity showed a $23 \%$ inhibition at t1 but returned to initial (to) levels at t2. A decay in oxygen consumption was observed after the correction for mitochondrial content. Lipid peroxidation of cell membranes remained unchanged.

Short-time smoking causes an acute and reversible mitochondrial complex IV inhibition in human mononuclear cells. These results suggest that smoke itself is one of the causes for the decrease of complex IV activity observed in chronic smokers. Eur Respir J 2004; 23: 214-218.
Mitochondrial Research Laboratory, Muscle Research Unit, Dept of Internal Medicine, Hospital Clínic, Institut d'Investigacions Biomèdiques August Pi i Sunyer (IDIBAPS) and University of Barcelona, Barcelona, Catalonia, Spain.

Correspondence: Ò. Miró, Muscle Research Unit, Dept of Internal Medicine, Hospital Clínic, Villarroel 170, 08036 Barcelona, Catalonia, Spain.

Fax: 34932279365

E-mail: omiro@clinic.ub.es

Keywords: Carbon monoxide toxicity, cytochrome oxidase, mitochondrial diseases, smoking

Received: April 62003

Accepted after revision: September 222003

This study was supported by Promoción General del Conocimiento PM99-0038 and Premi Fi de Residència 1999 of Hospital Clínic i Provincial de Barcelona.
Tobacco consumption causes damage in lungs and many other tissues and organs. Its devastating consequences are mediated by some of the $>4,000$ compounds contained in tobacco smoke [1]. Some of these compounds constitute themselves a major exogenous source of reactive oxygen species (ROS), as well as exhibiting a capacity for increasing endogenous ROS production via activation of inflammatoryimmune processes [2]. The major consequence for cell biology of the increase in ROS content is to enhance oxidative damage of some biological molecules of crucial relevance for cellular functions, such as deoxyribonucleic acid (DNA), proteins and lipids, which leads to a deterioration or loss of their physicochemical properties and functions [3]. Increasing attention has been paid in the recognition of relevance that such an oxidative damage could play in tobacco-mediated diseases, since greater lipid peroxidation [4], DNA oxidation and DNA repair activity [5-7] have been demonstrated in smokers compared with nonsmokers [8].

Mitochondria are one of the most important endogenous sources of ROS, since side reactions of the mitochondrial respiratory chain $(\mathrm{MRC})$ with molecular oxygen $\left(\mathrm{O}_{2}\right)$ directly generate such toxic oxygen metabolites [9]. Some of the chemicals contained in tobacco smoke have been suggested to interfere with different compounds of the MRC electron transport [10], which could result in an increased production of ROS. However, to date there have been few studies on the relationship between tobacco consumption and mitochondrial activity in humans.

It has been recently demonstrated by the authors that a decrease in mitochondrial cytochrome c oxidase activity in peripheral blood mononuclear cells (PBMC) from chronic smokers was associated with an increased membrane lipid peroxidation [11]. However, it is not known if such decrease in cytochrome c oxidase activity is due to the effects of tobacco smoke itself or, alternatively, it is a collateral event associated with damage in other organs induced by the smoking habit. In order answer this question, in the present study the authors investigated the acute effects of smoking in MRC from human PBMC. If acute smoking has effects on MRC function, it would implicate that such mitochondrial dysfunction could be of pathophysiological relevance in some smoking-related diseases.

\section{Subjects and methods}

\section{Subject selection}

A total of 20 nonsmoking young healthy subjects with similar physical activity $[12,13]$ were selected, recruited by an advertisement in the University of Barcelona Campus. All subjects gave their informed written consent to be included in the study. The Ethical Committee of the Hospital Clínic, Institut d'Investigacions Biomèdiques August Pi i Sunyer, Barcelona, approved the protocol.

\section{Proceedings}

The 20 selected subjects were allocated to a diet without an excess of antioxidants for 2 weeks [14, 15]. Sincerity 
about nonsmoker status was ascertained by means of two nonprogrammed determinations of carboxyhaemoglobin $(\mathrm{COHb})$ levels (Blood gas Analyzer CIBA-CORNING 800 System; Basel, Switzerland) and carbon monoxide in exhaled air (COEA) levels by means of an electrochemical transducer (Dräger Pac III; Dräger Safety Inc, Pittsburgh, PA, USA). All subjects had $\mathrm{COHb}$ levels $<2 \%$ and COEA $<6 \mathrm{ppm}$. After this period, subjects smoked five filtered cigarettes (nicotine $0.8 \mathrm{mg}$, tar $11 \mathrm{mg}$ ) in $45 \mathrm{~min}$. Individuals who did not increase by three times their basal levels of $\mathrm{COHb}$ at the end of the smoking $(n=5)$ were excluded.

In all 15 remaining subjects (25 \pm 4 yrs; nine males) COEA was determined and $30 \mathrm{~mL}$ of peripheral blood was obtained before smoking (t0), 1 min after the last cigarette (t1) and $24 \mathrm{~h}$ later (t2). $\mathrm{COHb}$ levels were measured with $3 \mathrm{~mL}$ of each sample. PBMC (lymphocytes and monocytes) were isolated by means of Ficoll's gradient. The final protein concentration was quantified according to Bradford's method [16].

\section{Mitochondrial assays}

PBMC was chosen for mitochondrial assays as it is a standard procedure for the investigation of respiratory chain disorders in humans [17], is a minimally invasive test for volunteers, and would establish the relationship of $\mathrm{COHb}$ levels with COEA levels.

Enzyme activity. Measurement of enzyme activity of individual complexes of the MRC was performed spectrophotometrically (UVIKON 920; Kontron, Schlieren, Switzerland). Complex II, III, and IV activities were determined following RUSTIN et al. [17] methodology, slightly modified for complex IV measurement [18]. Complex I and V cannot currently be accurately measured in PBMC [17].

Oxidative activity. $\mathrm{O}_{2}$ utilisation was measured polarographically in $250 \mu \mathrm{l}$ of standard medium ( $\mathrm{pH} \mathrm{7.4)} \mathrm{with} \mathrm{a} \mathrm{Clark}$ electrode in a water-jacketed cell at $37^{\circ} \mathrm{C}$ (Hansatech Instruments Limited $\mathbb{R}$, Norfolk, UK) according to RUSTIN et al. [17].

Correction of absolute activities by mitochondrial content (relative activities). Relative activities were established by dividing absolute enzyme and oxidative activities by citrate synthase activity [19, 20], which was assessed spectrophotometrically [17].

\section{Peroxidation of lipid membranes}

Loss of cis-parinaric acid fluorescence was used to measure lipid peroxidation [21]. PBMC protein $(100 \mu \mathrm{g})$ was put in $3 \mathrm{~mL}$ of phosphate buffered serum containing cis-parinaric acid (5 mM) (Molecular Probes $\mathbb{R}$, Eugene, OR, USA). Loss of fluorescence was measured with a fluorescence spectrophotometer (Hitachi F-2000, Tokyo, Japan) in the dark at $37^{\circ} \mathrm{C}$ for $30 \mathrm{~min}$ at $3 \mathrm{~min}$ intervals.

\section{Statistical analysis}

Mean \pm SD and percentages were used for quantitative and qualitative variables, respectively. Comparisons between results at $\mathrm{t} 0, \mathrm{t} 1$ and $\mathrm{t} 2$ were carried out using a paired t-test after assessing the normality of the distribution (KolmogorovSmirnov's test) and the equality of variances (Levene's test). An ANOVA model for repeated measures was used for comparison of cis-parinaric fluorescence curves at $\mathrm{t} 0, \mathrm{t} 1$ and $\mathrm{t} 2$ to search for intergroup differences with time. Values of $\mathrm{p}<0.05$ were considered statistically significant.

\section{Results}

$\mathrm{COHb}$ levels of participants increased from $0.5 \pm 0.3 \%$ at basal conditions (to) to $3.3 \pm 1.5 \%$ immediately after smoking (t1) $(\mathrm{p}<0.001)$. An identical pattern was recorded for COEA, which rose from $2.9 \pm 2.5 \mathrm{ppm}$ (t0) to $26.1 \pm 9.9 \mathrm{ppm}$ (t1) $(\mathrm{p}<0.001)$. According to these findings, cigarette smoke inhalation was considered effective. At $\mathrm{t} 2$, both markers of tobacco smoke exposition returned to initial (t0) values $(0.6 \pm$ $0.3 \%$ for $\mathrm{COHb}$ and $3.9 \pm 2.3 \mathrm{ppm}$ for COEA; nonsignificant difference with respect to t0 levels for both).

PBMC and mitochondria content did not differ along the times of study in the different samples. PBMC content $(\mathrm{mg}$ of protein $\cdot \mathrm{mL}^{-1}$ ) was $15.3 \pm 3.6$ at $\mathrm{t} 0,13.98 \pm 4.21$ at $\mathrm{t} 1$ and $14.2 \pm 5.0$ at $\mathrm{t} 2$ (nonsignificant difference), and cytrate syntase activity $\left(\mathrm{nmol} \cdot \mathrm{min}^{-1} \cdot \mathrm{mg}^{-1}\right.$ of PBMC protein) was $143.4 \pm 35.8$ at $\mathrm{t} 0,145.3 \pm 45.3$ at $\mathrm{t} 1$ and $134.9 \pm 36.7$ at $\mathrm{t} 2$ (nonsignificant difference).

Effects of smoking on MRC are showed in figures 1 and 2. Smoking caused an immediate decrease of complex II, III and IV enzyme activities, but the decrease was statistically significant only for complex IV (cytochrome c oxidase), which decreased from $49.4 \pm 17.1 \mathrm{nmol} \cdot \mathrm{min}^{-1} \cdot \mathrm{mg}^{-1}$ protein at to to
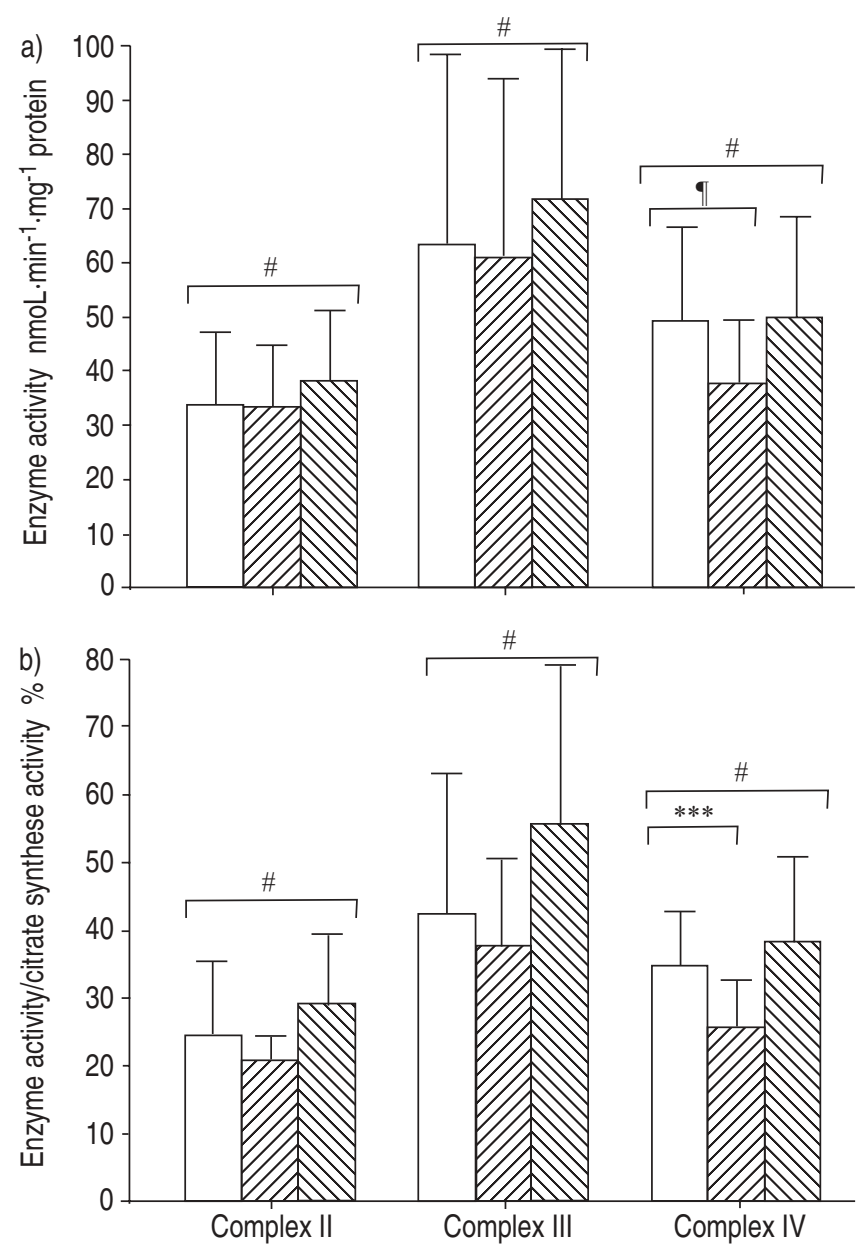

Fig. 1. - a) Absolute enzyme activities and b) relative enzyme activities. $\square$ : before smoking; $\square$ : immediately after smoking; $\nabla: 24 \mathrm{~h}$ after smoking. ${ }^{\#}$ : nonsignificant difference; ${ }^{\prime}: \mathrm{p}=0.002 ; * * *: \mathrm{p}<0.001$. 
$38.1 \pm 11.7$ at $\mathrm{t} 1(\mathrm{p}=0.002)$, and returned to basal levels $24 \mathrm{~h}$ later $\left(50 \pm 19.3 \mathrm{nmol} \cdot \mathrm{min}^{-1} \cdot \mathrm{mg}^{-1}\right.$ protein at t2) (fig. 1a).

After the correction of absolute enzyme rates by citrate synthase activity in order to obtain their relative activities, again only cytochrome c oxidase activity showed a same pattern of decrease associated with acute smoking, which decreased from $34.7 \pm 8.4 \%$ at to to $25.7 \pm 7.1 \%$ at $\mathrm{t} 1(\mathrm{p}<0.001)$ (fig. 1b).

Study of $\mathrm{O}_{2}$ consumption by PBMC showed no changes in spontaneous cell respiration or substrate oxidation with time when absolute activities were considered (fig. 2a). However, according to relative oxidative activities (fig. 2b), an overall decrease of $\mathrm{O}_{2}$ consumption after smoking (t1) was observed with all substrates, when compared with to values, being significant with pyruvate $(\mathrm{p}=0.01)$ and glycerol-3-phosphate $(\mathrm{p}<0.01)$. In spite of this decrease of $\mathrm{O}_{2}$ consumption, a tendency to enhance spontaneous cell oxidation rate (fig. 2b), that became significant at $\mathrm{t} 2$ was observed.

Finally, the study of lipid peroxidation of peripheral mononuclear cell membranes showed the same curves of loss of fluorescence of cis-parinaric acid before smoking, immediately after smoking, and $24 \mathrm{~h}$ after smoking (nonsignificant difference) (fig. 3).

\section{Discussion}

The present study investigated the effects of acute smoking on MRC components of PBMC in healthy, nonsmoking
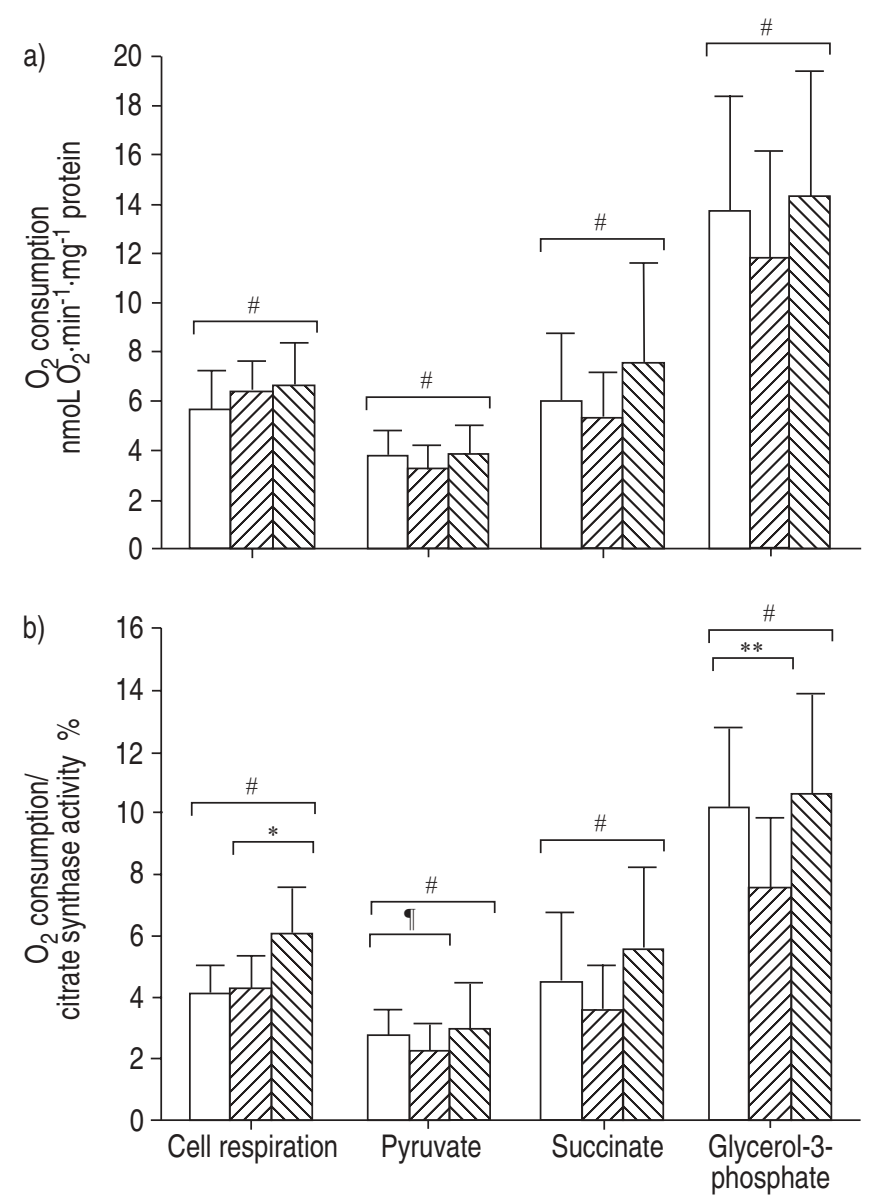

Fig. 2.-a) Absolute oxidation rates and b) relative oxidation rates. $\mathrm{O}_{2}$ : oxygen. $\square$ : before smoking; $\square$ : immediately after smoking; $\nabla$ : $24 \mathrm{~h}$ after smoking. ${ }^{\#}$ : nonsignificant difference; ${ }^{\pi} \mathrm{p}=0.01 ; *: \mathrm{p}<0.05$; $* *: \mathrm{p}<0.01$.

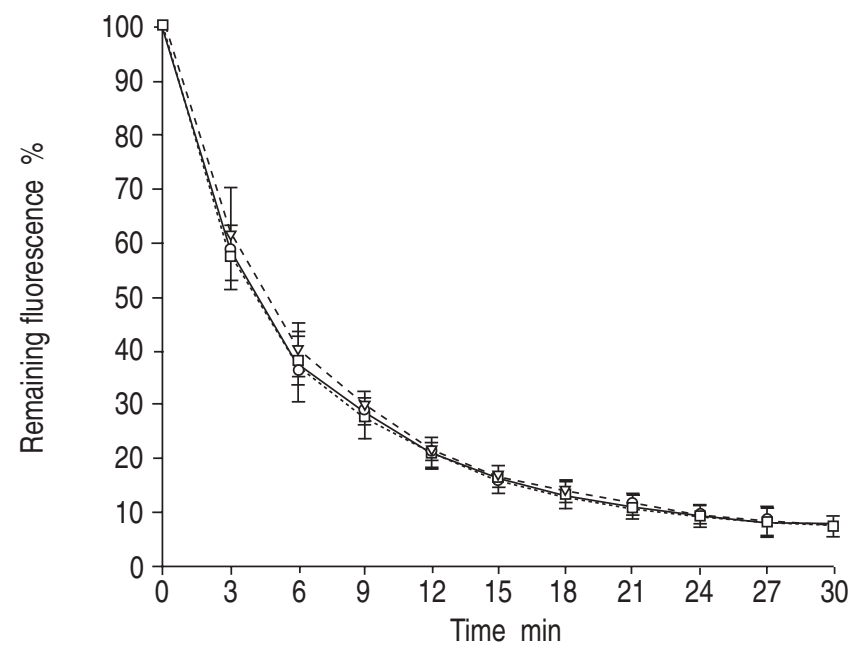

Fig. 3.-Curves of fluorescence of cis-parinaric acid. $\square$ : before smoking; $\bigcirc$ : immediately after smoking; $\nabla: 24 \mathrm{~h}$ after smoking. Error bars show SD.

subjects with a similar physical activity $[12,13]$ and illness was excluded by means of medical history, physical examination and routine blood analyses. Smoke inhalation was clearly effective in the studied individuals, as judged by the increase of $\mathrm{COHb}$ and COEA levels following smoking [22-24]. Subjects were assumed to have absorbed enough carbon monoxide $(\mathrm{CO})$ to detect any potential change in the studied parameters. On these experimental premises, a significant inhibition in absolute $(23 \%)$ and relative $(30 \%)$ cytochrome c oxidase activity was observed. With regard to relative oxidative activities, $\mathrm{O}_{2}$ consumption with pyruvate and glycerol-3-phosphate substrates showed a significant inhibition according to citrate synthase activity. All mitochondrial changes disappeared after $24 \mathrm{~h}$ of smoking abstinence, when blood $\mathrm{COHb}$ and COEA levels had also returned to basal values. These findings cannot be explained by any variability in the mitochondrial yield of samples at different times of the study, since citrate synthase activity was similar in all of them. Therefore, the observed effects should arise from direct and/or indirect actions of one or more of the components of tobacco smoke.

GvozdjáKovÁ et al. [25] and GvozDJAK et al. [26] demonstrated a decrease in cytochrome c oxidase activity of heart muscle mitochondria from rabbits inhaling cigarette smoke and noted that this decrease was higher in proportion to the length of the smoke exposure. In humans, ORLANDER et al. [27] and LARSSON and ORLANDER [28] found a decrease in cytochrome c oxidase activity from skeletal muscle mitochondria from chronic smokers, but did not give any information about MRC function after smoking cessation. More recently, the current authors have reported that tobacco is a confounding factor in studies concerning MRC function [12] and have demonstrated a $23 \%$ inhibition of cytochrome c oxidase activity in PBMC of heavy smokers with an average $\mathrm{COHb}$ of $4.8 \%$ [24]. Therefore, data from the current study from nonsmokers adds further evidence to previous studies and clearly indicates that smoking itself causes an immediate and transient alteration of cytochrome c oxidase activity.

The overall results of the current study have shown a $23 \%$ inhibition of cytochrome c oxidase, together with a significant decrease in the $\mathrm{O}_{2}$ consumption of MRC for pyruvate and glycerol-3-phosphate substrates and a nonsignificant change in succinate substrate, as well as significant enhanced spontaneous respiratory activity in intact PBMC after $24 \mathrm{~h}$ of smoking cessation. This increase in cell respiration was an 
unforeseen finding because it occurred $24 \mathrm{~h}$ after smoke exposure, when the remainder of MRC parameters were already normal. Hypothetical steps at which such an upregulation could occur include changes in nonmitochondrial oxidation, adenosine triphosphatease activity and/or mitochondrial proton leak [24]. In any case, those results suggest that such a degree of cytochrome c oxidase inhibition in short-time smoke inhalation is high enough to cause a disturbance of mitochondrial oxidative processes and a measurable but reversible decay in mitochondria energy production.

Although pathological effects after chronic exposure to some chemical agents are not always mediated through the same cellular and molecular pathways as an acute reaction, in the acute model of smoking in the current study a similar MRC inhibition was found to that in chronic smokers [24]. However, in the authors' opinion the ultimate toxic effect of smoking is more severe in chronic exposure, since enhanced lipid peroxidation was found in heavy smokers [24], though not after acute smoking, indicating ultimately a failure in the adaptative processes in heavy smokers. Therefore, the effect of cytochrome c oxidase inhibition on cell function in vivo in long-term smoking, together with other many disturbing tobacco-related factors, such as hypoxia, vitamin and antioxidant deficiencies, cyanide and other toxic substances, could contribute to an overall decrease of oxidative capacity, resulting in high free-radical production, mitochondrial DNA damage and cell death or proliferation [29-31]. All these events would be especially harmful in target organs and tissues, such as the lungs and bronchial epithelium.

The specific relevance of this cytochrome $c$ oxidase inhibition in whole-cell metabolism remains unclear, since cells normally use only $10-20 \%$ of the maximal velocity of an enzymatic reaction of the enzyme, and therefore to inhibit cellular respiratory rates a greater inhibition than that observed would be needed. Although this MRC dysfunction cannot be explained by the pathophysiology of smoking consequences, the authors believe that chronic and persistent inhibition should be considered as another factor in cellular injury, especially in cells already damaged by other physiopathological mechanisms of cigarette smoke. Additionally, the effects of tobacco smoke (either acute or chronic) are not exerted equally on all tissues. For example, respiratory tract epithelium and the lungs have a higher exposure to the physical and chemical effects of tobacco compounds, while consequences in other organs are related to their energy dependence status. Thus, in respiratory tract epithelium and the lungs, a higher enzyme activity inhibition could lead to a higher mitochondrial dysfunction that could contribute to less removal of bronchial secretions (due to bronchial epithelium ciliar misfunction), less response to infections (due to macrophage misfunction), and carcinogenesis [32, 33]. Moreover, in high energy dependent tissues, such as the brain, heart and muscle, an abnormal cytochrome c oxidase activity could contribute to the damage associated with tobacco consumption via a chronic decrease on whole mitochondria oxidative capacity [27, 28, 34-37]. Finally, as seen in many hypoxic circumstances [38], arteriopathy and chronic obstructive pulmonary disease could also contribute to mitochondrial injury.

Some authors have suggested that $\mathrm{CO}$ could be responsible for the decrease of cytochrome c oxidase activity [27]. This hypothesis is supported by the findings in patients suffering from acute, pure $\mathrm{CO}$ poisoning (COHb levels $\sim 20 \%$ ), in whom a severe and persistent inhibition of cytochrome c oxidase activity of $50-90 \%$ was demonstrated. This has been recently confirmed in vitro [39]. The binding of $\mathrm{CO}$ to cytochrome aa3, a component of cytochrome c oxidase, is the responsible for its deleterious effect [40-42] on this MRC enzyme [11]. Since acute smoking could be considered as a type of acute $\mathrm{CO}$ poisoning, although not pure (other components of cigarette smoke, such as cyanide [43], could also contribute to cytochrome c oxidase inhibition) and of a lower intensity, the authors believe that most considerations generally accepted for true CO poisoning could also apply for some disturbances that subjects with a chronic smoking habit will develop.

In conclusion, the decrease of mitochondrial complex IV activity that was found in peripheral blood mononuclear cells from acute smokers suggests that smoke itself is one of the causes of some enzyme inhibition observed in chronic smokers. However, the ultimate consequences of such longterm enzyme inhibition in tobacco-related diseases of the lung and other tissues in chronic smokers remain to be established.

\footnotetext{
Acknowledgements. The authors would like to thank A. Beato and S. López their valuable technical support.
}

\section{References}

1. Pryor WA, Arbour NC, Upham B, Church DF. The inhibitory effect of extracts of cigarette tar on electron transport of mitochondria and submitochondrial particles. Free Radic Biol Med 1992; 12: 365-372.

2. Lyons MJ, Gibson JF, Ingram DJE. Free-radicals produced in cigarette smoke. Nature 1958; 181: 1003-1004.

3. Kalra J, Chaudhary AK, Prasad K. Increased production of oxygen free radicals in cigarette smokers. Int $J$ Exp Path 1991; 72: 1-7.

4. Morrow JD, Frei B, Longmire AW, et al. Increase in circulating products of lipid peroxidation (F2.isoprostanes) in smokers. Smoking as a cause of oxidative damage. $N$ Engl J Med 1995; 332: 1198-1203.

5. Asami S, Hirano T, Yamaguchi R, Tomioka Y, Itoh H, Kasai $H$. Increase of a type of oxidative damage, 8-hydroxyguanine, and its repair activity in human leukocytes by cigarette smoking. Cancer Res 1996; 56: 2546-2549.

6. Priemé H, Loft S, Klarlund M, Gronbaek K, Tonnesen P, Poulsen HE. Effect of smoking cessation on oxidative DNA modification estimated by 8 -oxo-7, 8 -dihydro-2'-deoxyguanosine. Carcinogenesis 1998; 19: 347-351.

7. Piperakis SM, Visvardis EE, Sagnou M, Tassiou AM. Effects of smoking and aging on xoidative DNA damage of human lymphocytes. Carcinogenesis 1995; 19: 695-698.

8. Vineis P, Caporaso N. Tobacco and cancer: epidemiology and the laboratory. Environ Health Perspect 1998; 103: 156160.

9. Cadenas E, Davis KJ. Mitochondrial free radical generation, oxidative stress, and aging. Free Radic Biol Med 2000; 29: 222-230.

10. Smith PR, Cooper JM, Govan GG, Harding AE, Schapira AHV. Smoking and mitochondrial function: a model for environmental toxins. $Q J$ Med 1992; 86: 657-660.

11. Miró O, Casademont J, Barrientos A, Urbano-Márquez A, Cardellach F. Mitochondrial cytochrome c oxidase inhibition during acute carbon monoxide poisoning. Pharmacol Toxicol 1998; 82: 199-202.

12. Barrientos A, Casademont J, Rotig A, et al. Absence of relationship between the level of electron transport chain activities and aging in human skeletal muscle. Biochem Biophys Res Commun 1996; 229: 536-539.

13. Brierly EJ, Johnson MA, Bowman A, et al. Mitochondrial function in muscle from elderly athletes. Ann Neurol 1997; 41: $114-116$

14. Estruch R. Wine and cardiovascular disease. Food Res Intern 2000; 33: 219-226.

15. Marrugat J, Elosua R, Covas MI, Molina L, Rubiés-Prat J. 
Amount and intensity of physical activity, physical fitness, and serum lipids in men. Am J Epidemiol 1996; 143: 562-569.

16. Bradford M. A rapid and sensitive method for quantification of microgram quantities of protein utilizing the principle of protein-dye binding. Anal Biochem 1976; 72: 248-254.

17. Rustin $\mathrm{P}$, Chretien D, Bourgeron $\mathrm{T}$, et al. Biochemical and molecular investigations in respiratory chain deficiencies. Clin Chim Acta 1994; 228: 35-51.

18. Miró O, Cardellach F, Barrientos A, Casademont J, Rötig A, Rustin P. Cytochrome c oxidase assay in minute amount of human skeletal muscle using single wavelength spectrophotometers. J Neurosci Methods 1998; 80: 107-111.

19. Wang H, Hiatt WR, Barstow TJ, Brass EP. Relationships between muscle mitochondrial DNA content, mitochondrial enzyme activity and oxidative capacity in man: alterations with disease. Eur J Appl Physiol Occup Physiol 1999; 80: 22-27.

20. Fitts RH, Booth FW, Winder WW, Holloszy JO. Skeletal muscle respiratory capacity, endurance, and glycogen utilization. Am J Physiol 1975; 228: 1029-1033.

21. Hedley D, Chow S. Flow cytometric measurement of lipid peroxidation in vital cells using parinaric acid. Cytometry 1992; 13: 686-692.

22. Puente-Maestu L, Bahonza N, Perez MC, Ruiz de Ona JM, Rodriguez Hermosa JL, Tatay E. Relationship between tobacco smoke exposure and the concentrations of carboxyhemoglobin and hemoglobin. Arch Bronconeumol 1998; 34: 339-343.

23. Middleton ET, Morice AH. Breath carbon monoxide as an indication of smoking habit. Chest 2000; 117: 758-763.

24. Miró O, Alonso JR, Jarreta D, Casademont J, UrbanoMárquez A, Cardellach F. Smoking disturbs mitochondrial respiratory chain function and enhances lipid peroxidation on human circulating lymphocytes. Carcinogenesis 1999; 20: 1331-1336.

25. Gvozdjáková A, Kucharská J, Sány L, Gvozdjak J. The effect of cigarette smoke on cytochrome-oxidase of heart muscle. Cor Vasa 1984; 26: 466-468.

26. Gvozdjak J, Gvozdjakova A, Kucharska J, Bada V. The effect of smoking on myocardial metabolism. Czech Med 1987; 10: 47-53.

27. Örlander J, Kiessling KH, Larsson L. Skeletal muscle metabolism, morphology and function in sedentary smokers and nonsmokers. Acta Physiol Scand 1979; 107: 39-46.

28. Larsson L, Örlander J. Skeletal muscle morphology, metabolism and function in smokers and nonsmokers. A study on smoking-discordant monozygous twins. Acta Physiol Scand 1984; 120: 343-352.
29. Banzet N, Francois D, Polla BS. Tobacco smoke induces mitochondrial depolarization along with cell death: effects of antioxidants. Redox Rep 1999; 4: 229-236.

30. Vayssier M, Banzet N, Francois D, Bellmann K, Polla BS. Tobacco smoke induces both apoptosis and necrosis in mammalian cells: differential effects of HSP70. Am J Physiol 1998; 275: 771-779.

31. Loft S, Astrup A, Buemann B, Poulsen HE. Oxidative DNA damage correlates with oxygen consumption in humans. FASEB J 1994; 8: 534-537.

32. Romert L, Bernson V, Pettersson B. Effects of air pollutants on the oxidative metabolism and phagocytic capacity of pulmonary alveolar macrophages. $J$ Toxicol Environ Health 1983; 12: 417-427.

33. Kennedy JR, Allen PL. Effects of cigarette smoke residue on rabbit tracheal epithelium in organ culture. Arch Environ Health 1979; 34: 5-11.

34. Zhang J, Piantadosi CA. Mitochondrial oxidative stress after carbon monoxide hypoxia in the rat brain. J Clin Invest 1992; 90: 1193-1199.

35. Gvozdjakova A, Kucharska J, Gvozdjak J. Effect of smoking on the oxidative processes of cardiomyocytes. Cardiology 1992; 81: 81-84.

36. Lough J. Cardiomyopathy produced by cigarette smoke. Ultrastructural observations in guinea pigs. Arch Pathol Lab Med 1978; 102: 377-380.

37. Gvozdjáková A, Bada V, Sány L, et al. Smoke cardiomyopathy: disturbances of oxidative processes in myocardial mitochondria. Cardiovasc Res 1984; 18: 229-232.

38. McCard JM, Turrens JF. Mitochondrial injury by ischemia and reperfusion. Curr Top Bioenerget 1994; 17: 173-195.

39. Cardellach F, Alonso JR, Miró O, López S, Beato A, Casademont $\mathbf{J}$. Effect of carbon monoxide on cytochrome $c$ oxidase of skeletal muscle mitochondria. Toxicol Sci 2002; 66: 25 .

40. Piantadosi CA, Sylvia AL, Saltzman HA, Jöbsis-Vandervliet FF. Carbon monoxide - cytochrome interactions in the brain of the fluorocarbon-perfused rat. J Appl Physiol 1985; 58: 665-672.

41. Piantadosi CA, Sylvia AL, Jöbsis-Vandervliet FF. Differences in brain cytochrome responses to carbon monoxide and cyanide in vivo. J Appl Physiol 1987; 62: 1277-1284.

42. Coburn RF. Mechanisms of carbon monoxide toxicity. Prev Med 1979; 8: 310-322.

43. Pettersen JC, Cohen SD. The effects of cyanide on brain mitochondrial cytochrome oxidase and respiratory activities. J Appl Toxicol 1993; 13: 9-14. 